\title{
Mechanism of fat-binding and fat-contenting of the nanoparticles of a food supplement on the basis of double oxide of two- and trivalent iron
}

\author{
Iryna Tsykhanovska ${ }^{1}$, Victoria Evlash ${ }^{2}$, \\ Oleksandr Oleksandrov ${ }^{1}$, Tetiana Gontar ${ }^{1}$
}

\author{
1 - Ukrainian Engineering-Pedagogics Academy, Kharkiv, Ukraine \\ 2 - Kharkiv State University of Food Technology and Trade, Kharkiv, Ukraine
}

\section{Keywords:}

Fat-binding

Fat-contenting

Iron oxide

Food

Supplement

\section{Article history:}

Received

20.04.2018

Received in revised

form 28.09.2018

Accepted

27.12.2018

\section{Corresponding \\ author:}

Iryna Tsykhanovska

E-mail:

cikhanovskaja@

gmail.com

DOI:

$10.24263 / 2304-$

974X-2018-7-4-14

\section{Abstract}

Introduction. The mechanism of fattening and fat content of nanoparticles of a food additive on the basis of double oxide of twoand trivalent iron, which is represented by the model "Two-layer coordination", is substantiated.

Materials and methods. Nanoparticles of a dietary supplement based on bicarbonate and trivalent iron oxide, coated with linoleic acid and unrefined sunflower oil. Fat-retaining ability was investigated using IR-Fourier (FTIR) and energy-dispersive X-ray (EDX) spectroscopy, as well as scanning electron microscopy (TEM).

Results and discussion. The mechanism of fattening and fat content of nanoparticles of a food additive on the basis of double oxide of two- and trivalent iron, which is represented by the model "Twolayer coordination" is studied. The first adsorption layer is formed due to electrostatic interactions of polarized groups of lipids and ionized nanoparticles of a food additive and coordination bonds of $\mathrm{Fe}$ atoms, nanoparticles of a food additive with oxygenates of the $\mathrm{COO}^{-}$group of the "hydrophilic head" of the lipid; the second adsorption layer - due to electrostatic interactions of hydrophobic centers of the first adsorption layer and hydrocarbon "tails" of lipids.

The appearance of two new bands in IR spectra at: $\sim 1541 \mathrm{~cm}^{-1}$ and $\sim 1637 \mathrm{~cm}^{-1}$ subsolids bidentate adsorption and the formation of a carboxylate group (-COO-) in the "lipid-nanoparticle of a food additive" composition.

Microscopic studies have established the order of the average particle size: for pure food additives $-<\mathrm{d}>78 \pm 2,36 \mathrm{~nm}$; for the particles of the supplemented linoleic acid $-<\mathrm{d}>80 \pm 2,57 \mathrm{~nm}$; for the sunflower oil-added additives $-<\mathrm{d}>81 \pm 2,93 \mathrm{~nm}$.

Energizersispersion X-ray studies have established the elemental composition of "lipid-nanoparticles of food additives": for particles of pure food additive - $\mathrm{Fe} \mathrm{75,5 \% ;} \mathrm{O} \mathrm{24,} \mathrm{5 \% ;} \mathrm{for} \mathrm{particles} \mathrm{of} \mathrm{the} \mathrm{additive}$ covered with linoleic acid - Fe 45,6\%; O 34,7\%; C 19,7; for particles of an additive covered with sunflower oil - Fe 39,7\%; O 36,7\%; C $23,6 \%$.

Conclusions. The "Two-layer coordination" model was proposed for the first time to substantiate the mechanism of fattening and fat content of a nutritional supplement by nanoparticles on the basis of double-oxide and trivalent iron oxide. 


\section{Introduction}

One of the important functional and technological properties of food raw materials and food ingredients which determine the course of the technological processes and the quality of the finished product is fat-containing ability (FCA). Knowledge of the binding mechanisms and the fat content of raw materials will allow rational use of new types of food raw materials and food additives and predict the raw ingredients behavior in food systems (test and confectionery masses, minced meat, etc.) in the process of processing and storage of finished products.

Recently for FRA improving of the food systems the various nanopowders and food additives have been used, in particular, silver, iron oxides, titanium dioxide and silicon dioxide [1-6]. It is known to use nanopowder metal oxides in innovative animal products: zinc oxide, titanium dioxide and silicon dioxide [1]; as a food additive of complex action, $\left(\mathrm{Fe}_{3} \mathrm{O}_{4}\right)$ magnetite nanoparticles have been proposed [2]; nanopowders, magnetic nanoparticles of silver, silicon dioxide [3] magnetic nanoparticles of metals and metal oxides are also used in lipid, carbohydrate and protein compositions [4]; magnetite nanoparticles modifications with oleic acid [5] are used to create functional emulsions and oxide nanoparticles modifications and iron hydroxide with higher fatty acids and fats are used for aqueous suspensions [6]. The good FRA of nanopowder ingredients is associated with the high dispersion which allows not only to bind free fats, but also to keep them on the nanoparticles surface during cooking, as well as to the good availability of numerous hydrophobic sites [1-5].

In the scientific works [3-5] a single - layer adsorption model (chemisorption) of fatty acids on the metal oxide nanoparticles surface is proposed.

A model of two-layer adsorption is also considered: the first monolayer occurs on the nanoparticle surface due to the fatty acids chemisorption and makes the particles superhydrophobic; the second - due to the interaction of hydrophobic sections of the first layer with alky substituents of fatty acids [6]. However, these assumptions are controversial and require the additional experimental confirmation.

The literature analysis [1-6] showed that there is the insufficient data on the mechanism substantiation of nanopowder of food additives, in particular, $\mathrm{Fe}_{3} \mathrm{O}_{4}$ nanoparticles in the food systems. $\mathrm{Fe}_{3} \mathrm{O}_{4}$ nanopowder is the main component of the food supplement "Magnetofood" which is a scientific development of the authors of this work. Nanopowder based on iron oxides $\mathrm{Fe}_{3} \mathrm{O}_{4}$ ("Magnetofood") has the great potential and carries the new functional and technological properties (emulsifying, water-binding, water-holding, fat-binding, fatretaining) and the advanced technological applications $[2,7,8]$. The nanoparticles interaction of $\mathrm{Fe}_{3} \mathrm{O}_{4}$ food additive ("Magnetofood") with the food systems biopolymers (proteins, proteids, carbohydrates, lipids) is a complex of complex chemical reactions. The supramolecular organization of $\mathrm{Fe}_{3} \mathrm{O}_{4}$ nanoparticles ("Magnetofood") and the of the organic matrix structure play an important role. The result is the formation of spatial nanostructures that significantly affect the functional and technological properties of raw materials and semifinished products (confectionery and dough masses, meat stuffing systems, etc.) [7, 8].

Therefore, the work on the creation of the new functional and technological properties of food systems with the help of nanopowder of the food additives of the complex action are relevant. In this case, it is important to understand the mechanisms of fattening and fat binding and fat-containing.

To explain the mechanism of fat-containing ability (FCA) of nanoparticles (NPs) of the food additive on the basis of $\mathrm{Fe}_{3} \mathrm{O}_{4}$ iron oxides ("Magnetofood") it is necessary to determine 
and understand the nature and strength of the interaction of $\mathrm{Fe}_{3} \mathrm{O}_{4}$ nanoparticles with triglycerides and higher fatty acids.

The research aim is to study the mechanism of fat binding and fat-containing with nanoparticles of a dietary supplement based on the double oxide of ferric and ferric iron.

To achieve the goal, the following tasks were set:

- to study by the IR-spectroscopy method of the of adsorption interaction mechanism of lipid molecules (in particular, linoleic acid and sunflower oil) with nanoparticles of a dietary supplement based on the double oxide of ferric and ferric iron

- to investigate by the method of transmission electron microscopy (TEM) the particle size and morphology of the experimental samples of a food additive based on the double oxide of ferrous and ferric iron pure and coated with linoleic acid and sunflower oil;

- to install energy dispersive X-ray spectroscopy (EDX) of the elemental composition of the experimental samples of a food additive based on the double oxide of two and trivalent iron pure and coated with linoleic acid and sunflower oil.

\section{Materials and methods}

\section{Materials}

Object of research: the mechanism of fat-containing ability of the powder ingredients of food raw materials, in particular nanoparticles of the food supplements based on iron oxides "Magnetofood".

\section{Subjects of research:}

- Sample 1 - a food additive based on iron oxides ("Magnetofood") is a highly dispersed nanopowder of the brown or black color with a particle size $\sim 80 \mathrm{~nm}$. According to the chemical composition of "Magnetofood" is the double ferrous oxide $\left(\mathrm{FeO} \cdot \mathrm{Fe}_{2} \mathrm{O}_{3}\right.$ or $\mathrm{Fe}_{3} \mathrm{O}_{4}$ ), obtained by the method of chemical co-precipitation from aqueous solutions of two- and trivalent ferrous salts in alkaline medium [8];

- Sample 2 - linoleic acid [company "CL Reachim" Ukraine], the storage period is 5 days before using;

- Sample 3 - unrefined sunflower oil ["Vinnytskaia industrial company ViOil", Ukraine]. The storage period is 5 days before using;

- Sample 4 - the food supplements nanoparticles based on iron oxides ("Magnetofood") coated with linoleic acid. We obtained dispersion of $1 \mathrm{~g}$ of nanoparticles of the "Magnetofood" supplement (sample 1) and 0,2 g of linoleic acid in $10 \mathrm{ml}$ of dimethylformamide for 12 hours at a temperature of $(50 \pm 1){ }^{\circ} \mathrm{C}$ and blowing a nitrogen stream over the reaction mixture surface. After cooling the suspension to $(20-25){ }^{\circ} \mathrm{C}$ the nanoparticles of the food supplement "Magnetofood", coated with linoleic acid were isolated by magnetic filtration and washed with an aqueous-ethanol mixture (1:1) 5-7 times. The final product was dried in vacuum at $(60 \pm 1){ }^{\circ} \mathrm{C}$ for 24 hours, the storage period is 1 hour to use;

- Sample 5 - the food supplements nanoparticles based on iron oxides ("Magnetofood") coated with unrefined sunflower oil. The experimental sample was obtained in the same way as sample 4 only particles of the "Magnetofood" food supplement were coated with unrefined sunflower oil. The storage period is 1 hour to use. 


\section{Research methods}

\section{IR-Fourier Spectroscopy (FTIR)}

The vibrational spectra of the experimental samples were obtained by FTIR spectroscopy on the Tensor 37 Fourier spectrometer from Bruker (Germany), controlled by the OPUS software package with the standard graduated capabilities in the frequency range (4000-400) $\mathrm{cm}^{-1}$ in the absorption format (IR Fourier spectra of samples 1, 4, 5 were removed in the tablets $\mathrm{KBr}$; samples 2, 3 - in the "liquid film").

\section{Scanning electron microscopy (TEM)}

The particle size determination and morphology in the experimental samples 1, 4 and 5 were performed by using a JSM-820 scanning electron microscope (JEOL) with the increasing possibility up to 150000 times. The obtained images in a planar geometry with the electron beam falling along the hexagonal axis and perpendicular to it were processed with the help of AutoCad 2014 and MathCad 2014 programs. Based on the obtained results, the particle distribution in the experimental samples $1,4,5$ was calculated by diameter. The particles number in the sample to determine the average values was at least 500 .

\section{Energy dispersive X-ray spectroscopy (EDX)}

To establish the elemental composition of the experimental samples $1,4,5$, a scanning electron microscope JSM-820 (JEOL) with an EDX connector was used. X-ray spectra were obtained by the bombarding experimental samples with the electrons using an acceleration voltage of $20 \mathrm{kV}$ (corresponding to the lines of the characteristic spectra of the Ferrum, Carbon and Oxygen). The installation of the elemental composition of the experimental samples $1,4,5$ was carried out by the analysis of the received spectra of characteristic X-ray radiation.

\section{Results and discussion}

The mechanism of the fat-containing abilities (FCA) of the dietary supplement nanoparticles based on the double oxide of ferric and ferric iron $\left(\mathrm{FeO} \cdot \mathrm{Fe}_{2} \mathrm{O}_{3}\right.$ or $\left.\mathrm{Fe}_{3} \mathrm{O}_{4}\right)$ can be represented by the model of "two-layer coordination". Figure 1 shows the ionic interactions between the ionized nanoparticles of the food additive "Magnetofood" and the charged carboxyl group $\left(\mathrm{COO}^{-}\right)$of higher fatty acids.

Figure 1 shows how probably the interactions of the carboxyl group of free fatty acids of fats and oils with ions of $\mathrm{NPs} \mathrm{Fe}_{3} \mathrm{O}_{4}$ which are characterized by the high binding energy ( $500-1000 \mathrm{~kJ} / \mathrm{mol}$ ), take place [5].

The ability of NPs of food supplement "Magnetofood" $\left(\mathrm{Fe}_{3} \mathrm{O}_{4}\right)$ to enter electrostatic (Figure 1) and coordination (Figure 2-4) interactions with hydrophilic centers of free fatty acids and triglycerides determines their chemisorption on the reactive surface of ionized nanoparticles "Magnetofood" $\left(\mathrm{Fe}_{3} \mathrm{O}_{4}\right)$. As a result, the first adsorption layer is formed on surface NPs of food supplement "Magnetofood" $\left(\mathrm{Fe}_{3} \mathrm{O}_{4}\right)$. Taking into account the above and previous studies of the chemical interactions of nanoparticles of metal oxides and carboxylates of higher fatty acids the interaction between hydrophilic centers of triglycerides and fatty acids with NPs of food supplement "Magnetofood" $\left(\mathrm{Fe}_{3} \mathrm{O}_{4}\right)$ can be represented by four types: monodentate, bridge (bidentate), chelating (bidentate) and ionic interaction [5]. The model of ionic interactions is considered in Figure1.

Figure 2 shows the formation mechanism of the monodentate complex of NPs of food supplement "Magnetofood" $\left(\mathrm{Fe}_{3} \mathrm{O}_{4}\right)$ with fatty (linoleic) acid. 


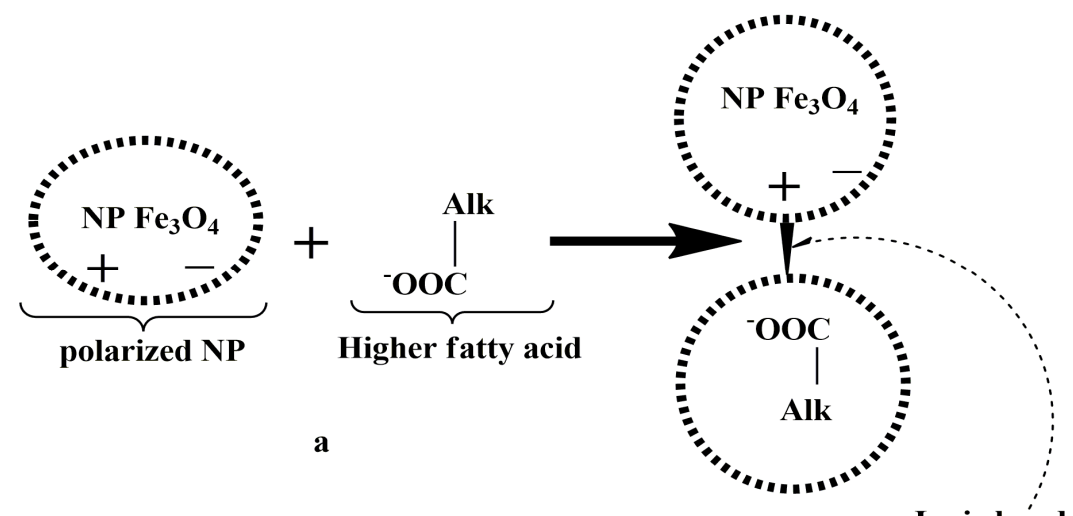

Ionic bónd

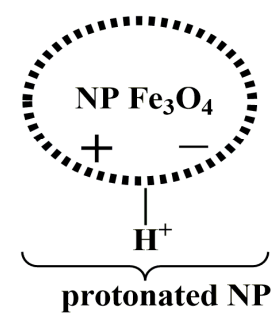

$+$

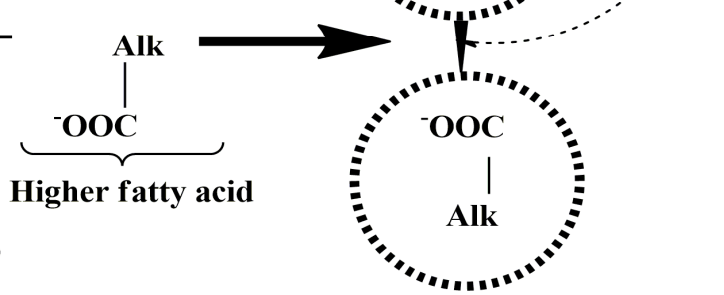

Figure 1. Ionic interactions between ionized nanoparticles of $\left(\mathrm{Fe}_{3} \mathrm{O}_{4}\right)$ food supplement "Magnetofod" and $\mathrm{COO}^{-}$-a group of higher fatty acids: a-polarized $\mathrm{NPs} \mathrm{Fe}_{3} \mathrm{O}_{4} ; \mathrm{b}$ - protonated $\mathrm{NPs} \mathrm{Fe}_{3} \mathrm{O}_{4}$
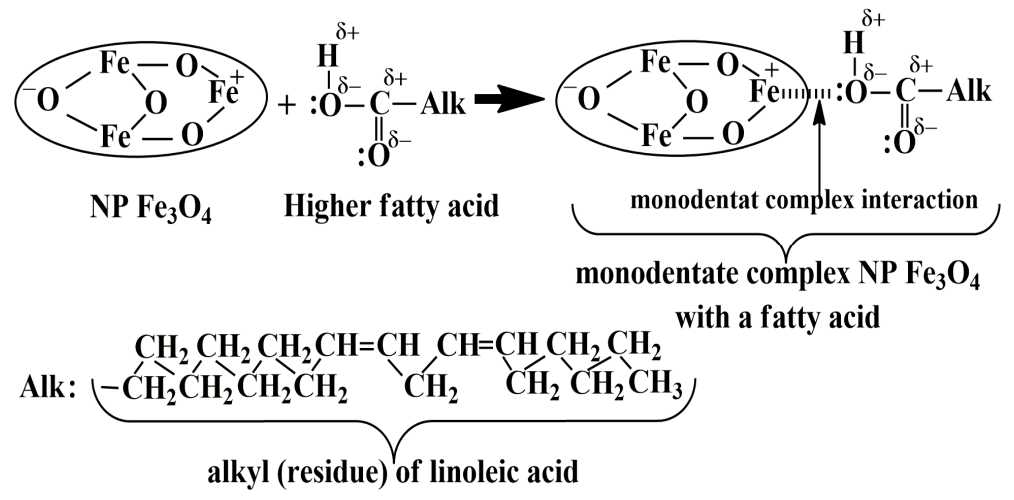

Figure 2. Formation of the monodentate complex of NPs of food supplement "Magnetofood" $\left(\mathrm{Fe}_{3} \mathrm{O}_{4}\right)$ with linoleic acid 
From Figure 2 it is evident that due to the complex interaction (electrostatic and coordination) one cation of the low-level iron of NPs of food supplement "Magnetofood" $\left(\mathrm{Fe}_{3} \mathrm{O}_{4}\right)$ binds to one carboxylic oxygen atom of linoleic acid. As a result, a unidirectional electrostatic complex is formed.

Figure 3 shows the formation mechanism of a bidentate (chelating) NPs complex of food supplement "Magnetofood" $\left(\mathrm{Fe}_{3} \mathrm{O}_{4}\right)$ with linoleic acid.

$$
\underbrace{\mathrm{NP} \mathrm{Fe}_{3} \mathrm{O}_{4}}_{\text {alkyl (residue) of linoleic acid }}
$$

Figure 3. Shows the formation mechanism of a bidentate (chelating) NPs complex of food supplement "Magnetofood" $\left(\mathrm{Fe}_{3} \mathrm{O}_{4}\right)$ with linoleic acid

This is a bidentate electrostatic complex in which one iron cation of a low-level fermentation NPs of food supplement "Magnetofood" $\left(\mathrm{Fe}_{3} \mathrm{O}_{4}\right)$ binds to two oxygen atoms of the carboxyl group of linoleic acid due to the complex interaction (electrostatic and coordination).

Figure 4 shows the formation mechanism of bidentate (bridging) NPs complex of food supplement "Magnetofood" $\left(\mathrm{Fe}_{3} \mathrm{O}_{4}\right)$ with linoleic acid. The interaction model shows that the formation of a bridge bidentate complex in which two iron cations of the low-level fermentation NPs of food supplement "Magnetofood" $\left(\mathrm{Fe}_{3} \mathrm{O}_{4}\right)$ binds to two oxygen atoms of the carboxyl group of linoleic acid due to the complex interaction (electrostatic and coordination).
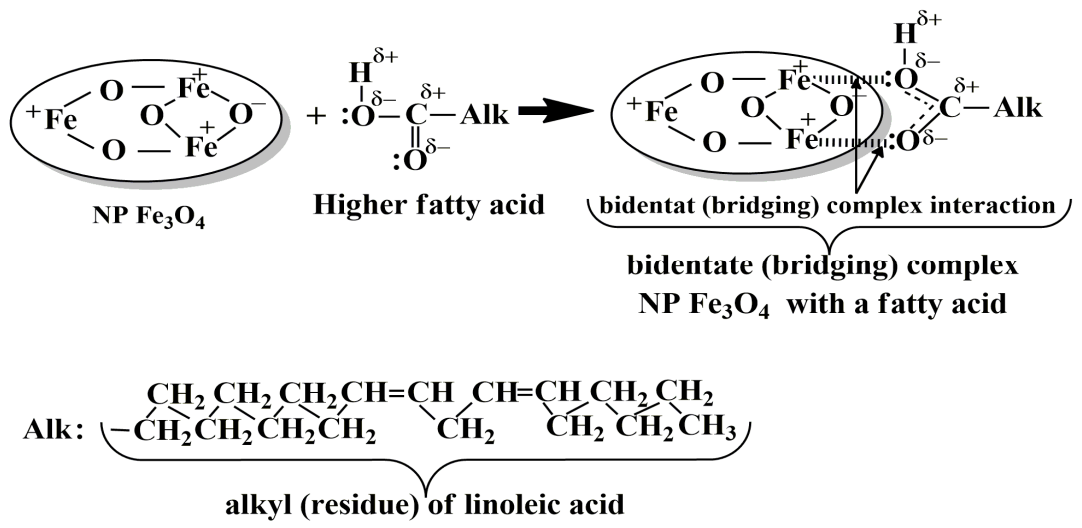

Figure 4. Formation of the bidentate (bridging) complex of NPs of food supplement "Magnetofood" $\left(\mathrm{Fe}_{3} \mathrm{O}_{4}\right)$ with linoleic acid 
As a result of the electrostatic and coordination interactions (Figures 1-4), the first adsorption layer on the NPs surface of food supplement "Magnetofood" $\left(\mathrm{Fe}_{3} \mathrm{O}_{4}\right)$ which is hydrophobic due to alkyl hydrophobic residues ("tails") of fatty acids (in particular, linoleic acids) and triglycerides.

Next, a second adsorption layer is formed due to the electrostatic hydrophobic interaction. The hydrophobic matrix of the first adsorption layer enters an electrostatic hydrophobic interaction with hydrophobic aliphatic "tails" of fatty acids and triglycerides.

Figure 5 shows the formation mechanism of the lipid associate of NPs of food supplement "Magnetofood" $\left(\mathrm{Fe}_{3} \mathrm{O}_{4}\right)$ due to hydrophobic interactions. From which it follows that the NPs Magnetofood food supplement $\left(\mathrm{Fe}_{3} \mathrm{O}_{4}\right)$ form lipid associates with fats and higher fatty acids, in particular with linoleic acid.

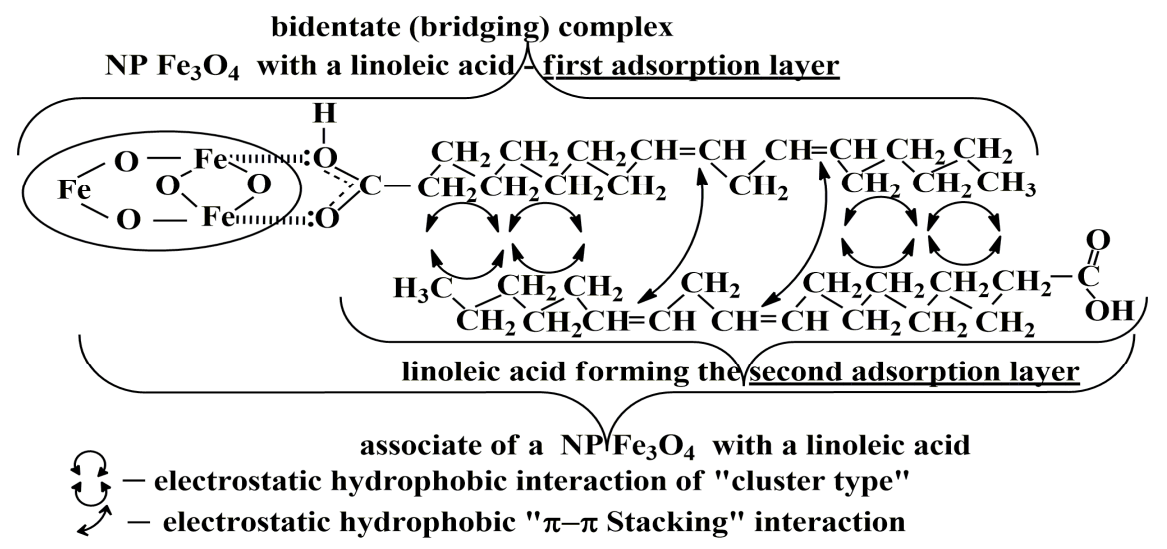

Figure 5. Formation of lipid associate of NPs of food supplement "Magnetofood" $\left(\mathrm{Fe}_{3} \mathrm{O}_{4}\right)$ with linoleic acid

Consequently, the second adsorption layer is formed due to the manifestation of the dispersion forces in sufficiently extended molecules of higher fatty acids and triglycerides in which there is a possibility of multicenter dispersion interaction.

As a result, the alkyl matrix of lipids is structured according to the type of Van-der Waals complexes, forming the second layer and the associate of nanoparticles of food supplement "Magnetofood" $\left(\mathrm{Fe}_{3} \mathrm{O}_{4}\right)$ with lipids.

\section{Results of IR-Fourier Spectroscopy (FTIR)}

To establish the adsorption interaction mechanism of the lipid molecules (in particular, linoleic acid and sunflower oil) with nanoparticles of food additive "Magnetofood" $\left(\mathrm{Fe}_{3} \mathrm{O}_{4}\right)$ IR-spectroscopic studies of experimental samples $1-5$ in the range $400-4000 \mathrm{~cm}^{-1}$ were conducted (Figure 6).

We can see in the spectrum of pure NPs of food additive "Magnetofood" $\mathrm{Fe}_{3} \mathrm{O}_{4}$. (the experimental sample 1) (Figure 6, a) the absorption line of the $\mathrm{Fe}-\mathrm{O}$ bond with a maximum at a value of $\sim 532 \mathrm{~cm}^{-1}$, is presented which agrees well with data from literary sources $\sim 530$ $\mathrm{cm}^{-1}[5,9,10]$.

The dislocation of the maximum of the corresponding absorption band of valence vibrations of the $\mathrm{Fe}-\mathrm{O}$ bond in the experimental samples 4 and 5 (Figure $6 d, e$ ) in the area $584 \mathrm{~cm}^{-1}$ can be explained by the effect of the surface molecules of linoleic acid and sunflower oil with their interference in the near-surface a layer of nanoparticles of food 
additive "Magnetofood" $\left(\mathrm{Fe}_{3} \mathrm{O}_{4}\right)$ and the chemical interaction with iron cations (Figures 1$5)$.

In the study of compositions "lipid - NPs of food additive $\mathrm{Fe}_{3} \mathrm{O}_{4}$ " the stretching frequency of the group $\mathrm{C}=\mathrm{O}$ have the greatest significance. The unexcited state of these fluctuation corresponds to an absorption band of $1710 \mathrm{~cm}^{-1}$ (Figure 6, b). And in the sunflower oil in the area of $1744 \mathrm{~cm}^{-1}$ there is an intense peak of valence fluctuations $\mathrm{C}=\mathrm{O}$ - bond (Figure 6, c). As you can see from Figure6, the adsorption of linoleic acid and sunflower oil on the NPs surface of "Magnetofood" food additive $\left(\mathrm{Fe}_{3} \mathrm{O}_{4}\right)$ (Figure $6 d, e$ ) shows the disappearance of this absorption band in the spectra of food additive $\left(\mathrm{Fe}_{3} \mathrm{O}_{4}\right)$ the particles coated with the lipid. And also two new bands appear at $1543 \mathrm{~cm}^{-1}$ (Figure 10,d) and $1540 \mathrm{~cm}^{-1}$ (Figure 6,e) and $1638 \mathrm{~cm}^{-1}$ (Figure 6,d) and $1636 \mathrm{~cm}^{-1}$ (Figure 6,e) which are characterized by the valence asymmetric $\left(v_{\text {as }}\right)$ and valence symmetric $\left(v_{\mathrm{s}}\right)$ of the carboxylate groups vibrations $\left(\mathrm{COO}^{-}\right)$. That is, the experimental data indicate that the lipid (carboxylic acids or triglycerides) of chemisorption on the nanoparticles surface of food additive $\mathrm{Fe}_{3} \mathrm{O}_{4}$ in carboxylate form (Figure 3, Figure 4 and Figure6, $d, e$ ) are using which the help of two Oxygen atoms. Which due to the electrostatic coordination interactions with $\mathrm{Fe}$ atoms are symmetrically coordinated with the surface of food additive $\mathrm{Fe}_{3} \mathrm{O}_{4}$ nanoparticles. The result is the formation of a monomolecular layer of a chemically adsorbed lipid (the first adsorption layer) on the nanoparticle surface of $\mathrm{Fe}_{3} \mathrm{O}_{4}$ (Figures 1-5) [11].

In the spectra of linoleic acid (Figure 6,b) and sunflower oil (Figure 6,c), the intense bands are observed with a maximum at $2926 \mathrm{~cm}^{-1}, 2856 \mathrm{~cm}^{-1}$ and $2924 \mathrm{~cm}^{-1}, 2854 \mathrm{~cm}^{-1}$ respectively. These peaks can be attributed to the asymmetric and symmetric $\left(v_{\text {as }}\right.$ and $\left.v_{\mathrm{s}}\right)$ vibrations of the $\mathrm{C}-\mathrm{H}$ bond in the $\mathrm{CH}_{2}$ group. Also, the spectra (Figure $6, b, c$ ) show the band of deformation $(\delta)$ vibrations $-\mathrm{CH}_{3}$ groups about $1360 \mathrm{~cm}^{-1}$, in linoleic acid, this band is very weak [9-11].

On the curves (Figure 6, $\boldsymbol{d}$ ) and (Figure 6,e) there is a displacement of these absorption bands to a lower frequency - in the area: $v_{\mathrm{as}}=2904 \mathrm{~cm}^{-1} ; v_{\mathrm{s}}=2831 \mathrm{~cm}^{-1}$ and $\delta=1350 \mathrm{~cm}^{-1}$, respectively. This is due, firstly, to the fact that the hydrocarbon chains of linoleic acid and sunflower oil triglycerides in the monolayer (the first adsorption layer) surrounding the nanoparticles of food additive "Magnetofood" are under the influence of the near-surface layer of NPs of food additive "Magnetofood" $\mathrm{Fe}_{3} \mathrm{O}_{4}$ and the chemical interaction with ferrum cations; and secondly, due to the hydrophobic interaction of hydrophobic centers of the first adsorption layer with the hydrocarbon chains of linoleic acid and sunflower oil triglycerides due to the dispersion forces. And this contributes to the formation of the second adabsorption layer on the surface of food additive $\mathrm{Fe}_{3} \mathrm{O}_{4}$ nanoparticles [12].

The unsaturated hydrocarbon chains which are a part of linoleic acid and sunflower oil triglycerides are manifested by the valence fluctuations of about $3008 \mathrm{~cm}^{-1}$ of the group $-\mathrm{CH}$ $=\mathrm{CH}-$ and a clear strip of deformation oscillations $(\delta) \mathrm{C}-\mathrm{H}$ of about $765 \mathrm{~cm}^{-1}$ (Figure $6 b$, c). On the structured nanoparticles of food additive $\mathrm{Fe}_{3} \mathrm{O}_{4}$ (Figure $6 d$, e), the displacement of these absorption bands is observed in the area: $v=3000 \mathrm{~cm}^{-1}$ and $\delta=752 \mathrm{~cm}^{-1}$, respectively [11]. This is due, firstly, to the effect of NPs of food additive $\mathrm{Fe}_{3} \mathrm{O}_{4}$ on the hydrocarbon chains of linoleic acid and sunflower oil triglycerides in the formation of the first adsorption layer; and secondly, with the electrostatic interactions of the hydrophobic centers of the first adsorption layer with the alkyl matrix of triglycerides and the alkaline tail of the linoleic acid of the type "Van der Waals complexes". This contributes to the structuring of the "hydrophobic matrix" of the "NPs-lipid system of food additive $\mathrm{Fe}_{3} \mathrm{O}$ " and the formation of the second adsorption layer on the surface nanoparticles of food additive $\mathrm{Fe}_{3} \mathrm{O}_{4}$ on which adsorbed lipids (linoleic acid or sunflower oil) have already been adsorbed in the first adsorption layer [13, 14]. 


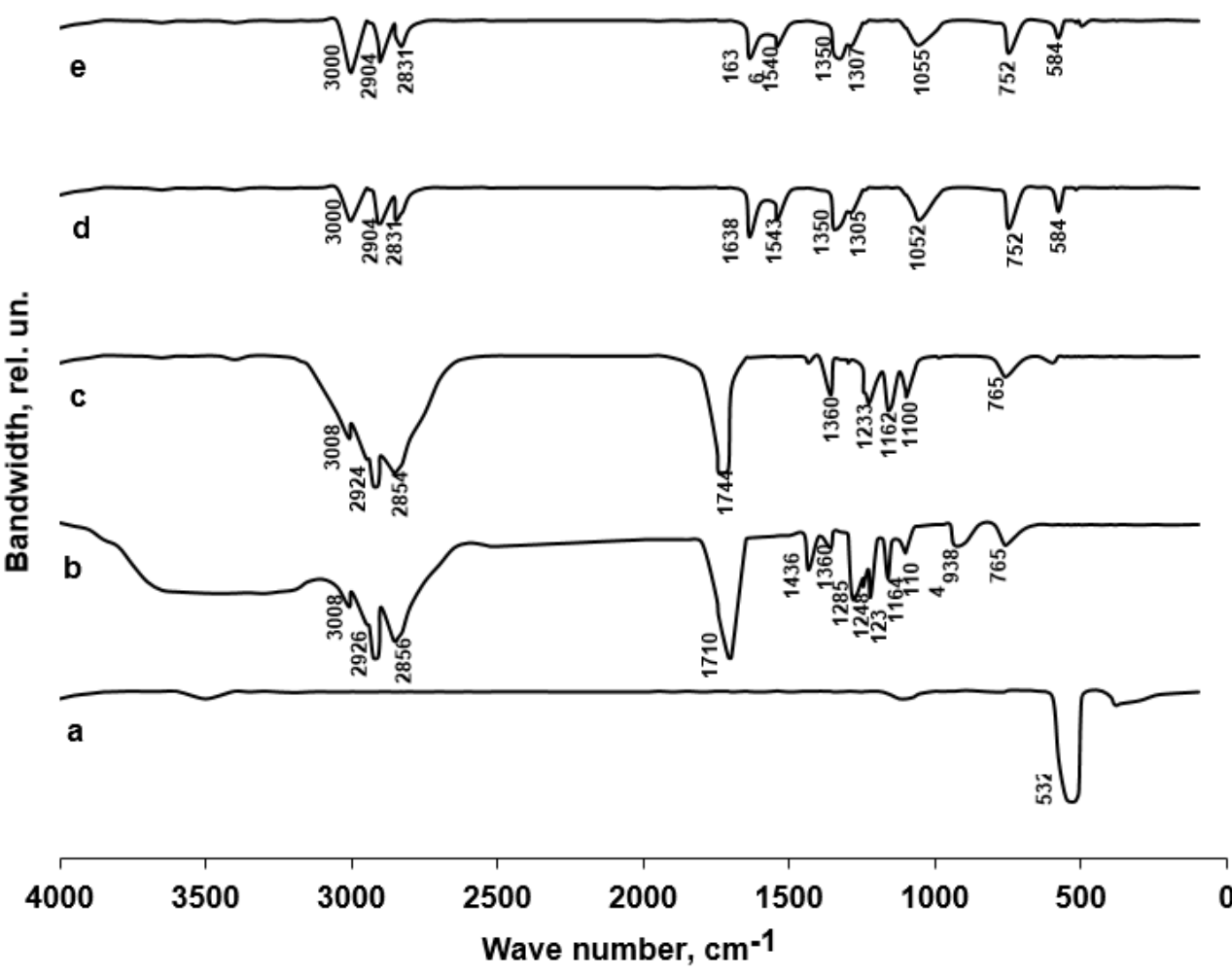

Figure 6. Fourier-IR spectra of the experimental samples of "lipid-NPs of food additive $\mathrm{Fe}_{3} \mathrm{O}_{4}$ compositions":

$a$ - finely-dispersed powder of food additive $\mathrm{Fe}_{3} \mathrm{O}_{4} ; b$-linoleic acid; $c$-sunflower oil; $d$-nanoparticles of food additive $\mathrm{Fe}_{3} \mathrm{O}_{4}$ covered with linoleic acid; $\boldsymbol{e}$-nanoparticles of food additive $\mathrm{Fe}_{3} \mathrm{O}_{4}$ covered with the sunflower oil

In the spectra of linoleic acid and sunflower oil (Figure $6, \boldsymbol{b}, \boldsymbol{c}$ ) three absorption bands are observed: a stronger band of about $1164 \mathrm{~cm}^{-1}(b)$ and $1162 \mathrm{~cm}^{-1}(c)$ and two less intensive bands of about $1236 \mathrm{~cm}^{-1}(b)$ and $1233 \mathrm{~cm}^{-1}(c)$ and $1104 \mathrm{~cm}^{-1}(b)$ and $1100 \mathrm{~cm}^{-1}(c)$. These are the valence fluctuations of the $\mathrm{C}-\mathrm{O}$ group. Also, in the spectrum of linoleic acid (Figure $6, b$ ), a double is noted: the first peak is at $1285 \mathrm{~cm}^{-1}$, the second one is at $1248 \mathrm{~cm}^{-1}$. The first arises as a result of the combination of plane deformation $\left(\delta_{\mathrm{p}}\right)$ oscillations of $\mathrm{O}-\mathrm{H}$ and $\mathrm{C}-\mathrm{O}$ bonds. The second of the peaks refers to the symmetric valence $\left(v_{\mathrm{s}}\right)$ oscillations of the $\mathrm{C}-\mathrm{O}$. Asymmetric valence $\left(v_{\text {as }}\right)$ oscillations of the $\mathrm{C}-\mathrm{O}$ bond of the carboxyl group of linoleic acid appeared on the doublet on the peak form at $1436 \mathrm{~cm}^{-1}$ [9-11].

In the spectra (Figure $6, d, e$ ) there are no such bands. And two new ones are appearing: at $1052 \mathrm{~cm}^{-1}$ and $1305 \mathrm{~cm}^{-1}$ (Figure 6, $d$ ) and $1055 \mathrm{~cm}^{-1}$ and $1307 \mathrm{~cm}^{1}$ (Figure 6,e) which are characteristic of plane deformation $\left(\delta_{\text {pd. }}\right)$ and valence $(v)$ oscillations of $\mathrm{C}-\mathrm{O}$ that interacts with polarized NPs of food additive $\mathrm{Fe}_{3} \mathrm{O}_{4}$ (Figure 1-5) [11].

The presence of the broad absorption band of average intensity for the spectrum of linoleic acid (Figure 6, $b$ ) in the range of $3200-3600 \mathrm{~cm}^{-1}$ associated with the characteristic 
vibrations of the surface $\mathrm{OH}$-groups. The non-plating $\left(\delta_{\text {npd. }}\right)$ deformation vibrations of the $\mathrm{O}-\mathrm{H}$ bond of the carboxyl group of linoleic acid are noted in the form of a band at $938 \mathrm{~cm}^{-1}$. Also you can see from Figure $6(c, d, e)$ in the spectrum of sunflower oil (Figure $6, c)$ and with the adsorption of linoleic acid (Figure 6,d) and sunflower oil (Figure 6,e) on the NPs of food additive $\mathrm{Fe}_{3} \mathrm{O}_{4}$ surface, these absorption bands disappear. This is confirmed by data on the absence of free hydroxy-groups on the surface of the "lipid-NPs of food additive $\mathrm{Fe}_{3} \mathrm{O}_{4}$ " system. These results confirm that oleic acid and triglycerides of sunflower oil are chemisorbed on nanoparticles of food additive $\mathrm{Fe}_{3} \mathrm{O}_{4}$ (Figures 1-5).

Obtained results of IR studies of the experimental samples in combination with previous studies of the processes of adsorption of fatty acids on particles of food additive $\mathrm{Fe}_{3} \mathrm{O}_{4}$ [911] confirm the formation mechanisms of the first lipid adsorption layer on the NPs of food additive $\mathrm{Fe}_{3} \mathrm{O}_{4}$, which can be represented by four types: monodentate, bridge (bidentate ), chelating (bidentate) and ionic interaction (Figure 1-5) [5].

The differences in the wave number values $\left(\Delta v_{0}\right)$ between the asymmetric $\left(v_{a s}\right)$ and symmetric $\left(\mathrm{v}_{\mathrm{s}}\right)$ stretching vibrations of the carboxylate $\mathrm{v}_{\text {as }}\left(-\mathrm{COO}^{-}-\right)$and $\mathrm{v}_{\mathrm{s}}\left(-\mathrm{COO}^{-}-\right)$groups (in the IR spectrum - Figure 6, $d, e$ ) can be used for the type identification of the interaction between carboxyl $\left(\mathrm{COO}^{-}\right)$lipids and a metal atom (in particular, $\mathrm{Fe}$ ) of nanoparticles of food additive $\mathrm{Fe}_{3} \mathrm{O}_{4}$

The largest deviation of the wave number $\Delta v_{\mathrm{o}}\left(200-320 \mathrm{~cm}^{-1}\right)$ corresponded to the monodentate interaction, and the smallest $-\Delta v_{0}\left(<110 \mathrm{~cm}^{-1}\right)$ - chelating (bidentate).

The mean average deviation $\Delta v_{0}\left(140-190 \mathrm{~cm}^{-1}\right)$ is characteristic for the bridge (bidentate) interaction. In this work, the $\Delta v_{o}$ value is $\sim 100 \mathrm{~cm}^{-1}\left(1638-1543=95 \mathrm{~cm}^{-1}\right.$, for sample d) $1636-1540=96 \mathrm{~cm}^{-1}$ for the sample $e$ ) and indicates the bidentate structure existence where two oxygen atoms of the carboxyl group of lipid which coordinated link with Ferum atoms surface of food additive $\mathrm{Fe}_{3} \mathrm{O}_{4}$ nanoparticles (Figures 4, 5).

Hence, the mechanism of fat-containing and fat binding capability of NPs of food additive "Magnetofood" $\left(\mathrm{Fe}_{3} \mathrm{O}_{4}\right)$ consists of the chemisorption of fats on their surface and can be represented by the "two-layer coordination" model:

- The first adsorption layer - due to the electrostatic interactions of polarized groups of lipids with the ionized nanoparticles of $\mathrm{Fe}_{3} \mathrm{O}_{4}$ additive and the coordination bonds of Ferum atoms of NPs of food additive $\mathrm{Fe}_{3} \mathrm{O}_{4}$ with Oxygen $\mathrm{COO}^{-}$- group of "hydrophilic head" of higher fatty acids and triglycerides of fat;

- The second adsorption layer - due to the electrostatic interactions of hydrophobic centers of the first adsorption layer and hydrocarbon tails of higher fatty acids and triglycerides of free fat.

\section{(TEM)}

Morphological analysis of experimental samples. Scanning Electron Microscopy

Particle size and morphology of experimental samples 1, 4 and 5 have been studied by using the transmission electron microscopy (TEM). Figure 7 shows the normalized distribution function of the particle size in the experimental samples 1,4 and 5 .

It is established that the distribution function is rather narrow and symmetric which tests the systems of the experimental samples of nanoparticles of food additive "Magnetofood" $\mathrm{Fe}_{3} \mathrm{O}_{4}$ as homogeneous with a low degree of polydispersity (Figure $7 a, b, c$ ). The established order of the average particle size is: for sample $1-<\mathrm{d}>\sim 78 \pm 2,36 \mathrm{~nm}$; for sample $4-<\mathrm{d}>\sim$ $80 \pm 2,57 \mathrm{~nm}$; for a sample of $5-<\mathrm{d}>\sim 81 \pm 2,93 \mathrm{~nm}$. 

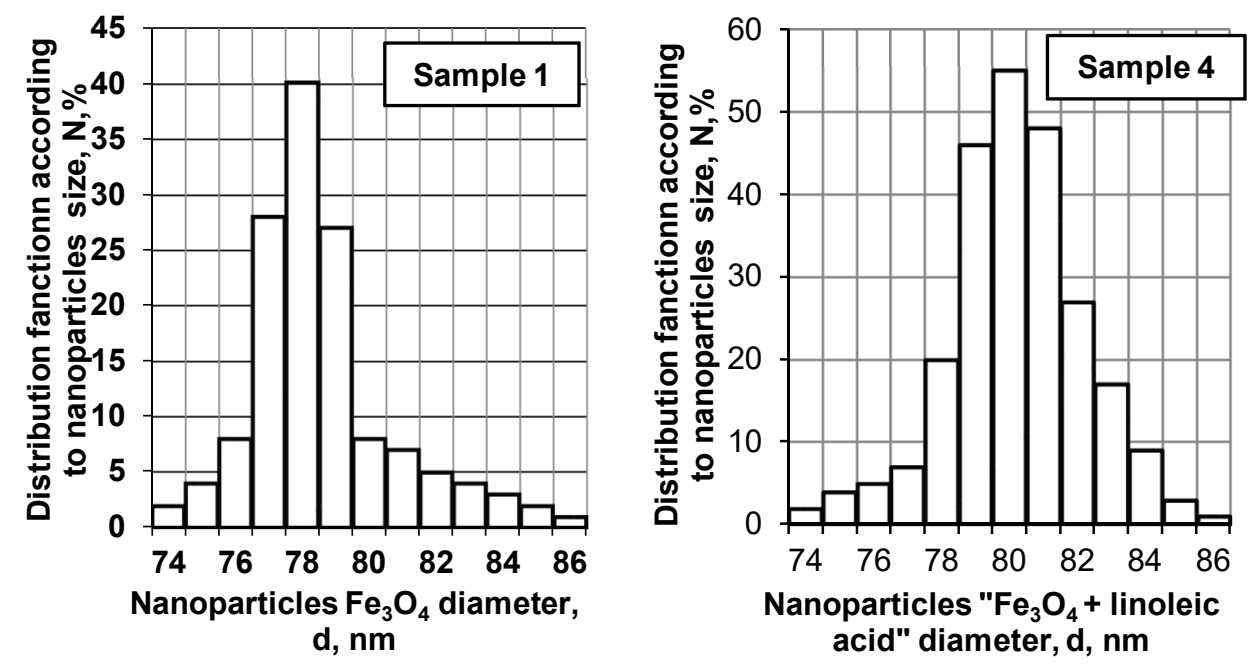

$a$

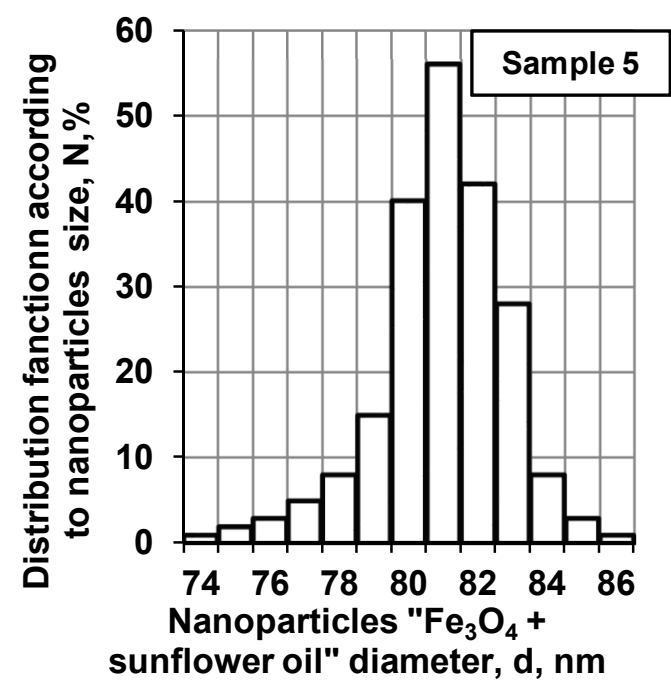

$c$

Figure 7. Diagrams of the particles distribution in order of size in the experimental samples: $a$ - synthesized fine powder of food additive $\mathrm{Fe}_{3} \mathrm{O}_{4}$; $b$ - nanoparticles of food additive $\mathrm{Fe}_{3} \mathrm{O}_{4}$ covered with linoleic acid; $c$ - nanoparticles of food additive $\mathrm{Fe}_{3} \mathrm{O}_{4}$ covered with sunflower oil

The increase in the particle size of food additive $\mathrm{Fe}_{3} \mathrm{O}_{4}$ in the experimental samples 4 and 5 compared with the pure NPs of food additive $\mathrm{Fe}_{3} \mathrm{O}_{4}$ (sample 1) is due to adsorption of linoleic acid and sunflower oil on the nanoparticles surface of food additive $\mathrm{Fe}_{3} \mathrm{O}_{4}$. That is, the total thickness of the $2 \mathrm{~d}$ lipid adsorption layer is: for linoleic acid (sample 4$)-2 \mathrm{~d}=$ $2 \cdot(1,10-1,25) \mathrm{nm}=(2,2-2,5) \mathrm{nm}$; for sunflower oil (sample 5$)-2 \mathrm{~d}=2 \cdot(1,4-1,6) \mathrm{nm}=$ $(2,8-3,2) \mathrm{nm}$. 


\section{Elemental analysis of the experimental samples. Energy dispersive X-ray spectroscopy (EDX)}

Using the EDX-spectra (Table 1) the elemental composition of the experimental samples of the composition "Lipid- $\mathrm{NPsFe}_{3} \mathrm{O}_{4}$ " was established.

Elemental composition of the experimental samples

Table 1

\begin{tabular}{|c|c|c|c|c|c|c|}
\hline \multirow{2}{*}{$\begin{array}{c}\text { Experimen- } \\
\text { tal } \backslash \text { samples }\end{array}$} & \multicolumn{6}{|c|}{ Elemental composition } \\
\cline { 2 - 7 } & Mass\% & Atomic\% & Mass\% & Atomic\% & Mass\% & Atomic\% \\
\hline Sample 1 & 75,5 & 42,9 & 24,5 & 57,1 & - & - \\
\hline Sample 4 & 45,6 & 37,5 & 34,7 & 26,6 & 19,7 & 35,9 \\
\hline Sample 5 & 39,7 & 35,5 & 36,7 & 29,6 & 23,6 & 34,9 \\
\hline
\end{tabular}

On X-ray spectra of the experimental samples $1,4,5$ the peaks are about 0,$8 ; 6,3$ and 6,8 $\mathrm{keV}$ and associated with the absorption of the kinetic energy of electrons by the Fe atom. The NPs spectra of food additive $\mathrm{Fe}_{3} \mathrm{O}_{4}$ which are covered with lipids contain two more peaks: about $0,27 \mathrm{keV}$ and $0,47 \mathrm{keV}$. These absorption bands belong to the atoms $\mathrm{C}$ and $\mathrm{O}[4,5]$. Moreover, the peak at $0,47 \mathrm{keV}$, characteristic of the atom $\mathrm{O}$ is also present in the spectrum of pure food additive $\mathrm{Fe}_{3} \mathrm{O}_{4}$ (sample 1). EDX-spectra analysis of the experimental samples $1,4,5$ shows that $\mathrm{Fe}, \mathrm{O}$ and $\mathrm{C}$ ( $\mathrm{H}$ can not be investigated) are the main components in the "lipid-NPs of food additive $\mathrm{Fe}_{3} \mathrm{O}_{4}$ ".

From the analysis of the experimental data (EDX-spectra) it follows that the experimental samples have the following chemical (qualitative and quantitative) composition: sample 1 (highly dispersed powder of food additive $\mathrm{Fe}_{3} \mathrm{O}_{4}$ ) $-\mathrm{Fe} 75,5 \%$; In $24,5 \%$; sample 4 (nanoparticles of food additive $\mathrm{Fe}_{3} \mathrm{O}_{4}$ covered with linoleic acid) - $\mathrm{Fe}$ $45,6 \%$; O 34,7\%; C 19,7\%; sample 5 (nanoparticles of food additive $\mathrm{Fe}_{3} \mathrm{O}_{4}$ covered with sunflower oil) - Fe 39,7\%; O 36,7\%; C 23,67\%. In the experimental samples 4, 5 a new chemical element (C) appears that is absent in the pure of food additive $\mathrm{Fe}_{3} \mathrm{O}_{4}$ (sample 1). The result indicates that NPs of food additive $\mathrm{Fe}_{3} \mathrm{O}_{4}$ was successfully synthesized (sample 1) and lipids (samples 4, 5) which chemisorption on the particles of food additive $\mathrm{Fe}_{3} \mathrm{O}_{4}$. The absorption band of atom $\mathrm{C}$ appeared in the samples 4,5 , confirms the process of adsorption and chemical interaction of particles of food additive $\mathrm{Fe}_{3} \mathrm{O}_{4}$ with lipids (in particular, linoleic acid and with triglycerides of sunflower oil).

\section{Conclusions}

1. The proposed model of "Two-layer coordination" of fats and higher fatty acids, in particular, of the linoleic acid on the surface NPs of food additive $\mathrm{Fe}_{3} \mathrm{O}_{4}$ : the first adsorption layer is formed due to the electrostatic interactions of polarized groups of lipids and ionized nanoparticles of food additive $\mathrm{Fe}_{3} \mathrm{O}_{4}$ and the coordination bonds of $\mathrm{Fe}$ atomic nanoparticles of food additive $\mathrm{Fe}_{3} \mathrm{O}_{4}$ with Oxygen $\mathrm{COO}^{-}-$a group of "hydrophilic head" of lipids; the second adsorption layer is due to the electrostatic interactions of hydrophobic centers of the first adsorption layer and hydrocarbon "tails" of lipids. 
2. Experimentally confirmed the mechanism of fat binding and fat content of nanoparticles of food additive on the basis of double oxide of two- and trivalent iron $\left(\mathrm{Fe}_{3} \mathrm{O}_{4}\right)$ which is represented by the model "Two-layer coordination":

- By the IR-Fourier spectroscopy method, the chemisorption of linoleic acid and 1-linoleyl-2oleoyl-3-linolenoylglycerol on the surface NPs of food additive $\mathrm{Fe}_{3} \mathrm{O}_{4}$ has been demonstrated: for example, in IR-spectrum of the experimental samples of NPs of food additive $\mathrm{Fe}_{3} \mathrm{O}_{4}$ covered with linoleic acid (sample 4) and sunflower oil (sample 5) appeared in two new bands at 1543 $\mathrm{cm}^{-1}$ (sample 4) and $1540 \mathrm{~cm}^{-1}$ (sample 5 ) and $1638 \mathrm{~cm}^{-1}$ (sample 4) and $1636 \mathrm{~cm}^{-1}$ (sample 5), which are characteristic of valence asymmetric $\left(v_{\text {as }}\right)$ and valence symmetric $\left(v_{\mathrm{s}}\right)$ oscillations of the carboxylate group $\left(\mathrm{COO}^{-}\right)$. The absorption band at $1710 \mathrm{~cm}^{-1}$ (linoleic acid is in the sample 2) and at $1744 \mathrm{~cm}^{-1}$ (sunflower oil is in the sample 3), characteristic of the valence fluctuations $\mathrm{C}=\mathrm{O}-$ bond, disappeared. That is, the experimental data of the IR-Fourier spectroscopy indicate that lipids (linoleic acid or triglycerides of sunflower oil) are chemisorbed on the nanoparticles surface of food additive $\mathrm{Fe}_{3} \mathrm{O}_{4}$ in the carboxylate form using two oxygen atoms. The result is the formation of a monomolecular layer of chemically adsorbed lipids on the nanoparticles surface of food additive $\mathrm{Fe}_{3} \mathrm{O}_{4}$. In the spectra of linoleic acid (example 2) and sunflower oil (sample 3) the intense bands are observed with peaks at $2926 \mathrm{~cm}^{-1}, 2856 \mathrm{~cm}^{-1}$ and $2924 \mathrm{~cm}^{-1}, 2854 \mathrm{~cm}^{-1}$, respectively and about $1360 \mathrm{~cm}^{-1}$. On the curves of the experimental samples 4 and 5 these absorption bands are shifted to a lower frequency and the region: $v_{\text {as }}=2904 \mathrm{~cm}^{-1} ; v_{\mathrm{s}}=2831 \mathrm{~cm}^{-1}$ and $\delta=1350 \mathrm{~cm}^{-1}$, respectively. This is due to the formation not only the first adsorption layer but also the formation of the second adsorption layer on the nanoparticles surface of food additive $\mathrm{Fe}_{3} \mathrm{O}_{4}$;

- The method of scanning electron microscopy revealed that the established order of the average particle size is: for sample $1-<\mathrm{d}>78 \pm 2,36 \mathrm{~nm}$; for sample $4-<\mathrm{d}>80 \pm 2,57 \mathrm{~nm}$; for a sample of $5-<\mathrm{d}>81 \pm 2,93 \mathrm{~nm}$;

- The method of energy dispersive X-ray spectroscopy the elemental composition of the experimental samples of food additive $\mathrm{Fe}_{3} \mathrm{O}_{4}$ was studied: sample 1 (highly dispersed powder of food additive $\mathrm{Fe}_{3} \mathrm{O}_{4}$ ) - $\mathrm{Fe} 75,5 \%$; O 24, 5\%; sample 4 (nanoparticles of food additive $\mathrm{Fe}_{3} \mathrm{O}_{4}$ covered with linoleic acid) - Fe 45,6\%; O 34,7\%; C 19,7; sample 5 (nanoparticles of food additive $\mathrm{Fe}_{3} \mathrm{O}_{4}$ covered with sunflower oil) - Fe 39,7\%; O 36,7\%; C 23,67\%.

The obtained results will allow to simulate the processes of fat-retaining capacity and fatbinding capability in the various food systems; the functional and technological characteristics of fat-containing compositions and the quality indicators of finished products.

\section{References}

1. Ramachandraiah K., Choi M.-J., Hong G.-P. (2018), Micro- and nanoscaled materials for strategy-based applications in innovative livestock products: a review, Trends in Food Science \& Technology, 71, pp. 25-35.

2. Ilyukha N. G., Barsova Z. V., Kovalenko V. A., Tsikhanovskaya I. V. (2010), Tekhnologiya proizvodstva i pokazateli kachestva pishchevoy dobavki na osnove magnetita, Vostochno-Yevropeyskiy zhurnal peredovykh tekhnologiy, 6(10), pp. 32-35.

3. Drmota A., Kosak A., Znidarsik A. (2008), A mechanism for the adsorption of carboxylic acids onto the surface of magnetic nanoparticles, Materials and technology, 42, pp. 7983. 
4. Mahdavi M., Ahmad M. B., Haron M. J., Namvar F., Nadi B., Ab Rahman M. Z., Amin J. (2013), Synthesis, Surface Modification and Characterisation of Biocompatible Magnetic Iron Oxide Nanoparticles for Biomedical Applications, Molecules, 18, pp. 7533-7548; doi:10.3390/molecules18077533.

5. Ling Z., Rong H., Hong-Chen G. (2006), Oleic acid coating on the monodisperse magnetite nanoparticles, Applied Surface Science, APSUSC-14301, 7, pp. 1-7, doi:10.1016/j.apsusc.2006.05.023.

6. Chernyshova I., Ponnurangam S., Somasundaran P. (2011), Adsorption of Fatty Acids on Iron (Hydr)oxides from Aqueous Solutions, Langmuir, 27 (16), pp. 10007-10018, DOI: $10.1021 / \mathrm{la} 2017374$.

7. Tsykhanovska I., Alexandrov A., Evlash V., Lazareva T., Svidlo K., Gontar T. (2018), Investigation of the moisture-retaining power of rye-wheat gluten and flour with polyfunctional food supplement "Magnetofood", Eureka: Life Sciences, 2(14), pp. 6776, doi: 10.21303/2504-5695.2018.00611.

8. (2018), Patent UA 126502, Kharchova dobavka "Mahnetofud", B.12.

9. Wang L.S. (2008), Synthesis, surface modification and characterization of nanoparticles, Advances in Nanocomposites, 34, pp. 289-322.

10. Hajdu A., Illes E., Tombacz E., Borbath I. (2009), Surface charging, polyanionic coating and colloid stability of magnetite nanoparticles, Colloids and Surfaces A, 347, pp. 104108.

11. Shen Y.F., Tang J., Nie Z.H., Wang Y.D., Ren Y., Zuo L. (2009), Preparation and application of magnetic $\mathrm{Fe}_{3} \mathrm{O}_{4}$ nanoparticles for wastewater purification, Sep. Purif. Technol., 68, pp. 312-319.

12. Skopenko V.V., Tsivadze A.Yu., Savranskiy L.I., Garnovskiy A.D. (2007), Koordinatsionnaya khimiya, Akademkniga, Moscow.

13. Steed J.W., Atwood J.L. (2000), Supramolecular chemistry, John Wiley \& Sons Ltd, Chichester.

14. Steed J.W., Atwood J.L. (2004), Encyclopedia of Supramolecular Chemistry, Marcel Dekker, 